\title{
Are biventricular assist devices underused as a bridge to heart transplantation in patients with a high risk of postimplant right ventricular failure?
}

Sven-Erik Bartfay, MD, ${ }^{\text {a }}$ Göran Dellgren, MD, PhD, ${ }^{\text {be }}$ Hans Lidén, MD, PhD, ${ }^{\text {b,e }}$

Mikael Holmberg, MD, PhD, ${ }^{\text {,e }}$ Jakob Gäbel, MD, PhD, ${ }^{\text {,e }}$ Bengt Redfors, MD, PhD,,${ }^{\text {, f }}$

Odd Bech-Hanssen, $\mathrm{MD}, \mathrm{PhD},{ }^{\mathrm{d}, \mathrm{e}}$ and Kristjan Karason, $\mathrm{MD}, \mathrm{PhD}^{\mathrm{a}, \mathrm{b}, \mathrm{e}}$

\begin{abstract}
Objective: Right ventricular failure in patients treated using left ventricular assist devices is associated with poor outcomes. We assessed the strategy of preplanned biventricular assist device implantation in patients with a high risk for right ventricular failure.

Methods: Between 2010 and 2014, we assigned 20 patients to preplanned biventricular assist device and 21 patients to left ventricular assist device as a bridge to heart transplantation on the basis of the estimated risk of postimplant right ventricular failure. Preimplant characteristics and postimplant outcomes were compared between the 2 groups.
\end{abstract}

Results: Patients with a biventricular assist device were younger, more often female, and more frequently had nonischemic heart disease than left ventricular assist device recipients. At preoperative assessment, biventricular assist device recipients had poorer Interagency Registry for Mechanically Assisted Circulatory Support profiles, a lower cardiac index, and more compromised right ventricular function. Survival on device to heart transplantation/weaning/destination for biventricular assist device and left ventricular assist device recipients was $90 \%$ versus $86 \%$ (not significant), with shorter heart transplantation waiting times for biventricular assist device recipients (median days, 154 vs 302, $P<.001$ ). Overall survival at 1 year was $85 \%$ (95\% confidence interval, 62-95) versus $86 \%$ (95\% confidence interval, 64-95) (not significant). The majority of both biventricular assist device and left ventricular assist device recipients could be discharged to home during the heart transplantation waiting time $(55 \%$ vs $71 \%$, not significant), and complication rates on device were comparable between groups (major stroke $10 \%$ vs $10 \%$, not significant).

Conclusions: Planned in advance, the biventricular assist device seems to be a feasible option as bridge to heart transplantation for patients with a high risk of postimplant right ventricular failure. The outcomes for these patients were similar to those observed for contemporary left ventricular assist device recipients, despite those receiving biventricular assist devices being more severely ill. (J Thorac Cardiovasc Surg 2017;153:360-7)

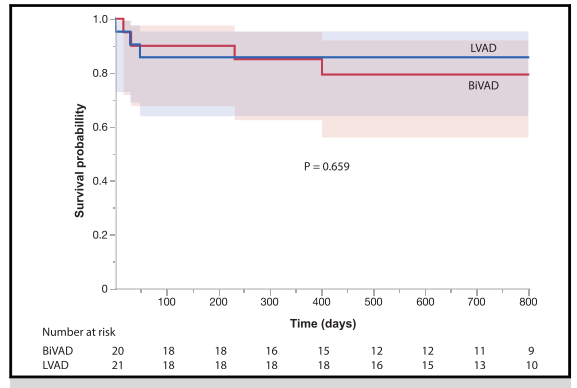

Survival probability in BiVAD and LVAD recipients.

\section{Central Message}

Aggressive use of a preplanned BiVAD as a bridge to transplantation for acutely ill patients with heart failure and for those with a high risk of postimplant RV failure seems to offer good long-term outcomes.

\section{Perspective}

$\mathrm{RV}$ failure in patients treated using LVAD is strongly associated with increased morbidity and mortality. For selected patients with a high risk of postimplant RV failure, a planned in advance BiVAD appears to be a viable strategy for bridge to HTx that may provide similar outcomes as for patients with adequate RV function treated with an LVAD alone.

See Editorial Commentary page 368.
From the Departments of ${ }^{\mathrm{a}}$ Cardiology, ${ }^{\mathrm{b}}$ Transplantation, ${ }^{\mathrm{c}}$ Anaesthesia and Intensive Care, and ${ }^{\mathrm{d}}$ Clinical Physiology, Sahlgrenska University Hospital; and ${ }^{\mathrm{e}}$ Institute of Medicine and ${ }^{\mathrm{f}}$ Institute of Clinical Sciences, University of Gothenburg, Gothenburg, Sweden.

This work was supported with grants from the Swedish Heart and Lung Foundation (ALFGBG-446811), the Jan Elgqvist Foundation, and the Sahlgrenska University Hospital ALF (20090614).
Received for publication Dec 11, 2015; revisions received Sept 21, 2016; accepted for publication Sept 26, 2016; available ahead of print Dec 9, 2016.

Address for reprints: Kristjan Karason, MD, PhD, Department of Cardiology, Sahlgrenska University Hospital, University of Gothenburg, SE- 413 45, Gothenburg, Sweden (E-mail: kristjan.karason@gu.se).

$0022-5223 / \$ 36.00$

Copyright () 2016 by The American Association for Thoracic Surgery http://dx.doi.org/10.1016/j.jtcvs.2016.09.084 


$\begin{array}{ll}\text { Abbreviations and Acronyms } \\ \text { AUC } & =\text { area under the curve } \\ \text { BiVAD } & =\text { biventricular assist device } \\ \text { CI } & =\text { confidence interval } \\ \text { ECC } & =\text { extracorporeal circulation } \\ \text { ECMO } & =\text { extracorporeal membrane } \\ & \text { oxygenation } \\ \text { HTx } & =\text { heart transplantation } \\ \text { ICU } & =\text { intensive care unit } \\ \text { INTERMACS }= & \text { Interagency Registry for } \\ & \text { Mechanically Assisted Circulatory } \\ & \text { Support } \\ \text { LVAD } & =\text { left ventricular assist device } \\ \text { MCS } & =\text { mechanical circulatory support } \\ \text { PCWP } & =\text { pulmonary capillary wedge } \\ & \text { pressure } \\ \text { RAP } & =\text { right atrial pressure } \\ \text { ROC } & =\text { receiver operating characteristic } \\ \text { RV } & =\text { right ventricular } \\ \text { RVSWI } & =\text { right ventricular stroke work index }\end{array}$

Scanning this QR code will take you to supplemental figure for this article.

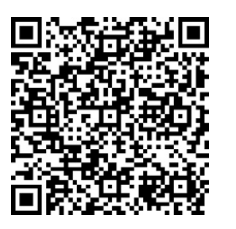

Right ventricular (RV) function is an important prognostic factor in patients with end-stage heart failure bridged to heart transplantation (HTx) with mechanical circulatory support (MCS). ${ }^{1} \mathrm{RV}$ failure occurs in up to $50 \%$ of patients after left ventricular assist device (LVAD) implantation and is strongly associated with increased mortality and morbidity. ${ }^{1,2}$ Despite later conversion to biventricular assist device (BiVAD) support, such patients have a worse outcome compared with those managed with LVAD alone. ${ }^{3}$

Poor survival among those with BiVAD support is not entirely unexpected because this therapy may arise from a subsequent conversion from LVAD, at a time when multiple organ failure developed. This calls into question whether patients with a high risk of RV failure may benefit from BiVAD implantation planned in advance. In a retrospective study, Fitzpatrick and colleagues ${ }^{4}$ reported that preplanned use of a BiVAD was associated with better outcomes than acute conversion from an LVAD to a BiVAD. Still, patients who received preplanned BiVAD did not reach the survival of those who received only an LVAD.

The evaluation of RV function is challenging, and it is difficult determine in advance whether there is the need for a BiVAD rather than an LVAD. Several retrospective single-center analyses have identified risk factors predictive of postimplant RV failure. ${ }^{1,3,5}$ Furthermore, different risk scores gathering several preoperative variables for stratifying the risk RV failure have been proposed. ${ }^{1,6,7}$ However, the validity of these risk scores has not been established.

Many centers avoid using planned BiVAD support as a bridge to transplantation because of uncertain outcomes, more demanding implantation techniques, higher costs, and significant patient discomfort during long-term support. Instead, patients with biventricular heart failure are likely to be subjected to a high-risk LVAD therapy or are not considered for ventricular assist device treatment at all. At Sahlgrenska University Hospital, where HTx wait times are fairly short (median time, 3 months), we have routinely applied preplanned BiVAD since 2010 as a treatment for patients considered to have a high risk of postimplant RV failure. The aim of this study was to describe the characteristics and outcomes of our patients receiving a BiVAD as a bridge to transplantation and to compare them with contemporary LVAD recipients.

\section{PATIENTS AND METHODS \\ Patient Demographics}

Between February 2010 and April 2014, 43 patients received a longterm MCS device at Sahlgrenska University Hospital. All devices were implanted as a bridge to transplantation because a program for destination therapy is not available at our center. For the present analysis, we included 41 patients. Two subjects with congenital heart disease were excluded. Among patients included, 20 were assigned to a preplanned pulsatile BiVAD (Excor, Berlin Heart GmbH, Berlin, Germany) and 21 received a continuous-flow LVAD (HeartMate II, Thoratec Corp, Pleasanton, Calif).

The decision as to which treatment strategy to use was based on the estimated risk for postimplant RV failure after a multidisciplinary evaluation of clinical, echocardiographic, and hemodynamic status. We did not apply uniform criteria or risk scores, but the presence of 1 or more of the following risk factors favored BiVAD implantation: Interagency Registry for Mechanically Assisted Circulatory Support (INTERMACS) profile 1, ongoing short-term circulatory assist, signs of multiple organ failure, echocardiographic signs of poor RV function, severe tricuspid regurgitation, tricuspid annular plane systolic excursion less than $0.72 \mathrm{~cm}$, invasive hemodynamic measures of right atrial pressure (RAP) greater than $16 \mathrm{~mm} \mathrm{Hg}$, or right ventricular stroke work index (RVSWI) less than $300 \mathrm{~mm} \mathrm{Hg} \times \mathrm{mL} / \mathrm{m}^{2}$. Blood samples were analyzed by the Central Laboratory of Sahlgrenska University Hospital (accredited according to European Norm 45,001). The study was approved by the ethical review board at the University of Gothenburg.

\section{Echocardiography}

Patients were examined preoperatively according to a standard transthoracic echocardiography protocol that included RV projections. All investigations were re-reviewed retrospectively and evaluated blindly with respect to study group. RV dysfunction was graded as none (0), mild (1), moderate (2), or severe (3). Tricuspid annular plane systolic excursion and tissue velocity imaging of the RV free wall were acquired. Tricuspid valve regurgitation was graded as none (0), mild (1), moderate (2), or severe (3).

\section{Invasive Hemodynamic Measurements}

In patients presenting INTERMACS levels 3 to 5 , a right heart catheterization was performed as part of routine workup during HTx 
evaluation. In those compatible with INTERMACS profiles 1 and 2, a hemodynamic profile was most often acquired in the ICU. For patients on short-term MCS, hemodynamic data were acquired before implantation or during a structured weaning attempt allowing for evaluation of RV function. RAP, mean pulmonary artery pressure, and pulmonary capillary wedge pressure (PCWP) were measured, and cardiac output was determined using the thermodilution technique. Pulmonary vascular resistance, central venous pressure/PCWP ratio and RVSWI were calculated.

\section{Right Ventricular Failure Risk Scores}

Patients were categorized using the INTERMACS clinical profiles. ${ }^{8}$ Also, 2 different RV failure risk scores, not used at the time of implant decision, were calculated retrospectively. The risk score developed by Matthews and colleagues ${ }^{6}$ is based on 4 variables, including vasopressor requirement creatinine, bilirubin, and aspartate aminotransferase. The risk score described by Fitzpatrick and colleagues ${ }^{7}$ consists of 6 variables: cardiac index, RVSWI, degree of RV dysfunction, creatinine, previous cardiac surgery, and systolic blood pressure.

\section{Surgical Procedure}

LVADs were implanted using a sternotomy and extracorporeal circulation (ECC). In most instances, the procedure was performed on a beating heart without crossclamping the aorta. Weaning from ECC was always slow and gradual with care taken to increase LVAD flow slowly to preserve RV function. Inhaled nitric oxide as a pulmonary vasodilator was used routinely and, if considered necessary, switched over to inhaled epoprostenol in the ICU.

BiVAD implantations also were performed using a sternotomy and ECC on a beating heart. Patients were first weaned from the ECC by connecting the Excor cannulas to a short-term MCS device (Rotaflow PLS system, Maquet, Germany). In our experience, this practice facilitates hemodynamic adjustment during weaning of the ECC and during the early postoperative phase. A few days later, when the patient had been found to be stable and neurologically intact, a second simple procedure was performed with the exchange of Rotaflow devices to 2 Excor pump houses. One advantage with the 2-step procedure is that there will be no waste of Excor pump houses in case of a postoperative disaster, such as a major stroke or death.

\section{Postoperative Management and Follow-up}

Heparin was initiated when bleeding had ceased (24-48) hours and activated partial thromboplastin time was targeted at 40 to 50 seconds. Warfarin treatment was started after removal of chest tubes with international normalized ratio targeted at 2.0 to 3.0 for LVAD recipients and at 2.5 to 3.5 for BiVAD recipients. A daily dose of $75 \mathrm{mg}$ aspirin was added. After stabilization, patients were transferred to the cardiology ward, where they were mobilized and given self-care training. For all patients receiving an LVAD, we aimed for home discharge before they were placed on the HTx waiting list. Our first BiVAD recipients were managed in hospital before transplantation, but later on also aimed for home discharge $(\mathrm{n}=11)$. All discharged patients were followed regularly at the outpatient clinic using a standard MCS protocol. The follow-up visits included routine testing to survey for patient-related or device-related adverse events. To reduce the HTx perioperative risk, we allocated in general a 3-month period for end-organ recovery and physiotherapy before patients were activated on the waiting list.

\footnotetext{
Statistics

Statistical analyses were performed with JMP 10 statistical software (SAS Institute, Inc, Cary NC). Data are presented as means and standard deviations, medians and interquartile ranges, or numbers and percentages. Comparisons between groups were performed with an unpaired $t$ test for normally distributed data, the Kolmogorov-Smirnov asymptotic test for
}

nonparametric data, and Fisher exact test for categoric data. Survival curves were generated using Kaplan-Meier estimates and comparison between groups used the log-rank test. Receiver operating characteristic (ROC) curves were plotted for RV risk failure scores, and areas under the curve (AUCs) were compared between groups with the chi-square test. The 3 LVAD recipients later converted to long-term BiVAD support were categorized as LVAD recipients in all analyses, except in the evaluation of RV failure risk scores, in which they were included in the BiVAD group. All tests were 2-tailed.

\section{RESULTS \\ Patient Characteristics}

Demographics, medical history, and preoperative laboratory values for the 2 study groups are shown in Table 1. Patients who required BiVAD were younger, more often female, and had a lower body surface area compared with those receiving LVAD. All BiVAD recipients had a nonischemic heart failure cause compared with approximately half of the LVAD recipients. Although BiVAD recipients tended to have somewhat higher liver function test results, the difference between groups was not statistically significant.

\section{Preimplant Right Ventricular Function}

Table 2 displays preoperative echocardiographic data, invasive hemodynamic measurements, need for circulatory/ ventilatory support, and risk scores for postimplant RV failure. The left ventricular ejection fraction was similar in both study groups. Those receiving a BiVAD had a more compromised RV function with lower tricuspid annular plane systolic excursion, lower RV free wall tissue velocity, and a higher degree of tricuspid valve regurgitation. BiVAD recipients also displayed a higher RAP, a lower mean pulmonary artery pressure and PCWP, a lower cardiac index, a higher central venous pressure/PCWP ratio, and a lower RVSWI. Although BiVAD recipients appeared to require more preoperative treatment with inotropes, short-term MCS, and mechanical ventilation, the differences between groups were not statistically significant. In the BiVAD group, 13 patients $(65 \%)$ were treated with short-term MCS for a median (interquartile range) of 7 (3-9) days. In the LVAD group, 8 patients $(38 \%)$ were treated with short-term MCS for a median (interquartile range) of 7.5 (4-12) days. A more detailed description of the different types of devices used for short-term circulatory support in the 2 study groups is presented in Figure E1. Among patients receiving BiVAD, $55 \%$ received implants as INTERMACS level 1 and 35\% received implants as INTERMACS level 2. The corresponding numbers for LVAD recipients were $29 \%$ and $19 \%$, respectively. BiVAD recipients displayed significantly higher risk scores for postimplant RV failure.

\section{Outcome}

The overall survival did not differ between BiVAD and LVAD recipients and was $85 \%$ (95\% confidence interval 
TABLE 1. Demographics, medical history, and preoperative laboratory values

\begin{tabular}{lccc}
\hline \multicolumn{1}{c}{ Variables } & $\begin{array}{c}\text { BiVAD } \\
(\mathbf{n}=\mathbf{2 0})\end{array}$ & $\begin{array}{c}\text { LVAD } \\
(\mathbf{n}=\mathbf{2 1})\end{array}$ & $\begin{array}{c}\boldsymbol{P} \\
\text { value }\end{array}$ \\
\hline Demographics & & & \\
Age $(\mathrm{y})$ & $40 \pm 14$ & $53 \pm 14$ & .005 \\
Female (vs male) sex & $9(45)$ & $1(5)$ & .003 \\
Caucasian (vs other) race & $18(90)$ & $21(100)$ & .232 \\
BMI $\left(\mathrm{kg} / \mathrm{m}^{2}\right)$ & $25.4 \pm 3.8$ & $26.6 \pm 4.1$ & .089 \\
BSA $\left(\mathrm{m}^{2}\right)$ & $1.90 \pm 0.26$ & $2.06 \pm 0.2$ & .046 \\
Medical history & & & \\
Hypertension & $0(0)$ & $1(5)$ & .232 \\
Diabetes & $1(5)$ & $6(29)$ & .093 \\
Atrial fibrillation/flutter & $4(21)$ & $3(15)$ & .695 \\
Myocardial infarction & $1(5)$ & $9(43)$ & .009 \\
Previous cardiac surgery & $4(20)$ & $3(15)$ & .696 \\
Nonischemic (vs ischemic) & $20(100)$ & $12(57)$ & .001 \\
$\quad$ HF cause & & & \\
Duration of heart failure (mo) & $6(1-48)$ & $39(0.5-83)$ & .423 \\
Laboratory values & & & \\
Hemoglobin (g/L) & $120 \pm 19$ & $129 \pm 20$ & .127 \\
Creatinine $(\mu$ mol/L) & $109 \pm 44$ & $118 \pm 41$ & .473 \\
AST $(\mu$ kat/L) & $0.63(0.43-1.1)$ & $0.52(0.42-0.75)$ & .273 \\
ALT $(\mu$ kat/L) & $0.77(0.42-1.5)$ & $0.63(0.40-1.48)$ & .344 \\
Bilirubin $(\mu$ mol/L) & $19(16-32)$ & $17(8-25)$ & .155 \\
\hline
\end{tabular}

Values are presented as means \pm standard deviation, numbers (\%), or medians (interquartile range). BiVAD, Biventricular assist device; $L V A D$, left ventricular assist device; $B M I$, body mass index; $B S A$, body surface area; $H F$, heart failure; $A S T$, aspartate aminotransferase; $A L T$, alanine aminotransferase.

[CI], 62-95) versus $86 \%(95 \% \mathrm{CI}, 64-95)$ at 1 year and $79 \%$ (95\% CI, 0.56-0.92) versus $86 \%(95 \% \mathrm{CI}, 64-95)$ at 2 years, respectively (Figure 1). The median time on device to transplantation or weaning for BiVAD recipients was 154 (95\% CI, 94-185) days, and time to transplantation or destination strategy for LVAD recipients was $302(95 \%$ CI, 189-426) days $(P<.001)$ (Figure 2).

In the BiVAD group, 17 patients underwent HTx and 1 patient was weaned $(90 \%)$. Two patients died on pump $(10 \%)$ : 1 of multiple organ failure at day 17 and 1 of a stroke at day 32. In the LVAD group, 16 patients underwent HTx; 1 patient is still on the waiting list, and in 1 patient the treatment strategy was changed to destination therapy after a stroke $(86 \%)$. Three LVAD recipients died while on device $(14 \%)$ : 1 of multiple organ failure at day $1 ; 1$ of sepsis, pump thrombosis, and a stroke at day 30; and 1 of subdural bleeding at day 49 .

\section{Complications}

The time in the ICU was similar for the BiVAD and LVAD groups (Table 3). The total hospital stay was somewhat longer for BiVAD recipients than for LVAD recipients, but this was not statistically significant. The majority of patients in both groups could be discharged to home during the wait for HTx.
TABLE 2. Preoperative echocardiographic data, invasive hemodynamic measurements, circulatory and ventilatory support, and risk scores

\begin{tabular}{|c|c|c|c|}
\hline Variables & $\begin{array}{c}\text { BiVAD } \\
(\mathbf{n}=\mathbf{2 0})\end{array}$ & $\begin{array}{c}\text { LVAD } \\
(\mathbf{n}=\mathbf{2 1})\end{array}$ & $\begin{array}{c}P \\
\text { value }\end{array}$ \\
\hline \multicolumn{4}{|l|}{ Echocardiographic measurements } \\
\hline Left ventricular ejection fraction (\%) & $18 \pm 10$ & $18 \pm 7$ & .927 \\
\hline Severe RV failure & $17(85)$ & $4(19)$ & $<.001$ \\
\hline TAPSE $(\mathrm{cm})$ & $1.2 \pm 0.3$ & $1.6 \pm 0.23$ & .001 \\
\hline $\begin{array}{l}\text { RV free wall peak tissue } \\
\text { velocity }(\mathrm{cm} / \mathrm{s})\end{array}$ & $7.2 \pm 1.8$ & $10.1 \pm 2.3$ & .005 \\
\hline TVR grade $(0-3)$ & $1.9 \pm 0.8$ & $1.3 \pm 0.8$ & .038 \\
\hline \multicolumn{4}{|l|}{ Invasive hemodynamic measurements } \\
\hline Heart rate (beats/min) & $95 \pm 29$ & $82 \pm 23$ & .220 \\
\hline Systolic blood pressure (mm Hg) & $93 \pm 11$ & $97 \pm 11$ & .191 \\
\hline RAP (mm Hg) & $14 \pm 5$ & $9 \pm 4$ & .007 \\
\hline $\begin{array}{l}\text { Mean pulmonary artery } \\
\text { pressure }(\mathrm{mm} \mathrm{Hg})\end{array}$ & $28 \pm 6$ & $36 \pm 10$ & .039 \\
\hline PCWP (mm Hg) & $20 \pm 5$ & $24 \pm 7$ & .049 \\
\hline Cardiac index $\left(\mathrm{L} / \mathrm{min} / \mathrm{m}^{2}\right)$ & $1.4 \pm 0.5$ & $1.9 \pm 0.3$ & .007 \\
\hline $\mathrm{SvO}_{2}(\%)$ & $51 \pm 9$ & $56 \pm 9$ & .183 \\
\hline $\begin{array}{l}\text { Pulmonary vascular resistance } \\
\text { (Wood Units) }\end{array}$ & $3.1 \pm 1.7$ & $3.1 \pm 2.2$ & .752 \\
\hline CVP/PCWP ratio & $0.71 \pm 0.26$ & $0.38 \pm 0.13$ & $<.001$ \\
\hline RVSWI $(\mathrm{mm} \mathrm{Hg} \times$ mL/m²) & $234 \pm 219$ & $607 \pm 278$ & .001 \\
\hline \multicolumn{4}{|l|}{ Circulatory and ventilatory support } \\
\hline Intravenous inotropic therapy & $18(90)$ & $15(71)$ & .237 \\
\hline Short-term circulatory assist & $13(65)$ & $8(38)$ & .121 \\
\hline Mechanical ventilation & $8(40)$ & $4(19)$ & .181 \\
\hline \multicolumn{4}{|l|}{ Risk scores } \\
\hline INTERMACS profile 1-2 (vs 3-5) & $18(90)$ & $10(48)$ & .006 \\
\hline $\begin{array}{l}\text { Risk score } 1 \text { (Matthews } \\
\text { and colleagues }{ }^{6} \text { ) }\end{array}$ & $4.0 \pm 2.3$ & $3.3 \pm 3.6$ & .474 \\
\hline $\begin{array}{l}\text { Risk score } 2 \text { (Fitzpatrick } \\
\text { and colleagues }{ }^{7} \text { ) }\end{array}$ & $52 \pm 14$ & $28 \pm 15$ & $<.001$ \\
\hline
\end{tabular}

Values are presented as means \pm standard deviation, numbers (\%), or medians (interquartile range). BiVAD, Biventricular assist device; $L V A D$, left ventricular assist device; $R V$, right ventricular; TAPSE, tricuspid annular plane systolic excursion; $T V R$, tricuspid valve regurgitation; $P C W P$, pulmonary capillary wedge pressure; $\mathrm{SvO}_{2}$, mixed venous oxygen saturation; $C V P$, central venous pressure; $R V S W I$, right ventricular stroke work index; INTERMACS, Interagency Registry for Mechanically Assisted Circulatory Support.

The absolute frequency of pump-related complications was similar in both groups (Table 3). When expressed as episodes per 100 patient-months, adverse events tended to be somewhat higher in the BiVAD group, but a statistically significant difference was observed only for minor stroke. Early postoperative continuous renal replacement therapy was required more often in LVAD recipients, but the difference between groups was not statistically significant. Four patients in the BiVAD had a stroke; 2 were major and 2 were minor with trivial residual symptoms. One of the patients with a major stroke died. One of the patients was weaned and died 5 months later of neurologic deterioration and worsening heart failure. Two patients in the LVAD group had a major stroke. For 1 of the patients, 


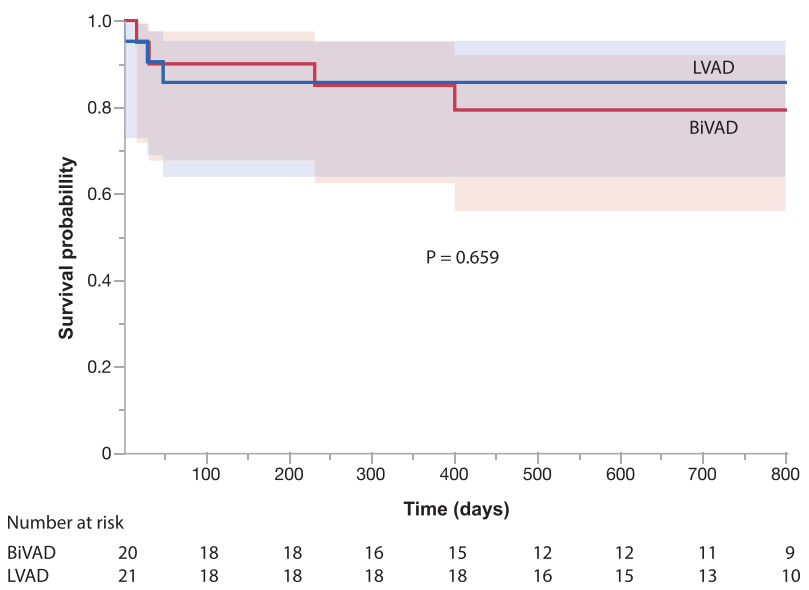

FIGURE 1. Survival probability for BiVAD and LVAD recipients. The shaded areas bounding the estimated functions for each group show $95 \%$ CIs. BiVAD, Biventricular assist device; $L V A D$, left ventricular assist device.

this was related to pump thrombosis and resulted in death. The second patient's treatment strategy was altered to destination therapy.

One patient in each group encountered driveline infection requiring intravenous antibiotics. Two LVAD recipients had recurrent bacteremia, probably due to pump colonization. Both remained on continuous antibiotic treatment until transplantation. There was 1 case of serious BiVAD malfunction due to membrane rupture in the left Excor pump. The patient recovered after treatment with extracorporeal membrane oxygenation (ECMO) and replacement of the pump house.

Significant RV failure after implantation developed in 5 LVAD recipients, defined as the need for inotrope support

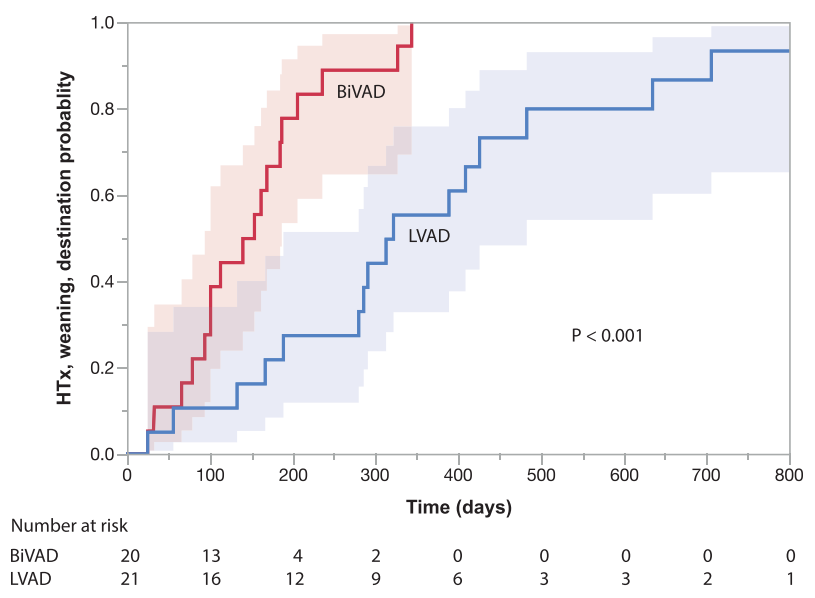

FIGURE 2. Time on device to transplantation/weaning/destination (censored for death) for BiVAD and LVAD recipients. The shaded areas bounding the estimated functions for each group show $95 \%$ CIs. HTx, Heart transplantation; BiVAD, biventricular assist device; $L V A D$, left ventricular assist device.
TABLE 3. Time hospitalized and pump-related complications

\begin{tabular}{|c|c|c|c|}
\hline Variables & $\begin{array}{l}\text { BiVAD } \\
(n=20)\end{array}$ & $\begin{array}{c}\text { LVAD } \\
(\mathbf{n}=\mathbf{2 1})\end{array}$ & $\begin{array}{c}P \\
\text { value }\end{array}$ \\
\hline \multicolumn{4}{|l|}{ Hospital stay and discharge } \\
\hline Time in the ICU (d) & $7(4-17)$ & $7(5-23)$ & .532 \\
\hline Time in hospital on device (d) & $62(36-90)$ & $44(30-57)$ & .133 \\
\hline Discharge to home & $11(55)$ & $15(71)$ & .341 \\
\hline \multicolumn{4}{|l|}{ Pump-related complications } \\
\hline Need for CRRT in the ICU & $1(5)$ & $6(29)$ & .093 \\
\hline Major stroke in each group & $2(10)$ & $2(10)$ & 1.000 \\
\hline Episodes per 100 patient-mo & 2.17 & 1.03 & .449 \\
\hline Minor stroke in each group & $2(10)$ & $0(0)$ & .232 \\
\hline Episodes per 100 patient-mo & 2.17 & 0 & .041 \\
\hline Pump thrombosis in each group & $0(0)$ & $1(5)$ & 1.000 \\
\hline Episodes per 100 patient-mo & 0 & 0.52 & .490 \\
\hline Mechanical pump failure in each group & $1(5)$ & $0(0)$ & 1.000 \\
\hline Episodes per 100 patient-mo & 1.08 & 0 & .148 \\
\hline Pump-related bacteremia in each group & $0(0)$ & $2(10)$ & .488 \\
\hline Episodes per 100 patient-mo & 0 & 1.03 & .329 \\
\hline $\begin{array}{l}\text { Driveline infection requiring IV } \\
\text { antibiotics in each group }\end{array}$ & $1(5)$ & $1(5)$ & 1.000 \\
\hline Episodes per 100 patient-mo & 1.08 & 0.52 & .592 \\
\hline RV failure & NA & $5(24)$ & \\
\hline $\mathrm{RV}$ failure requiring long-term assist & NA & $3(14)$ & \\
\hline
\end{tabular}

Values are presented as median (interquartile range) or numbers (\%) unless otherwise specified. BiVAD, Biventricular assist device; $L V A D$, left ventricular assist device; $I C U$, intensive care unit; $C R R T$, continuous renal replacement therapy; $I V$, intravenous; $R V$, right ventricular; $N A$, not available.

for more than 14 days, inhaled nitric oxide for 48 hours or more, or right-sided circulatory support. Two of these patients died (day 30 and day 49), and 3 patients required long-term RVAD support. For the survivors, the median time in the ICU was 28 days (range, 25-35), and the median total hospital stay on pump was 167 days (range, 25-210).

\section{Right Ventricular Failure Risk Scores}

ROC curves for the risk scores developed by Matthews and colleagues ${ }^{6}$ and Fitzpatrick and colleagues ${ }^{7}$ are shown in Figure 3. The AUC for the former was $0.72(95 \% \mathrm{CI}$, $0.55-0.89)(P=.028)$ and for the latter was $0.92(95 \%$ CI, 0.81-1.00) $(P<.001)$, with a strong trend toward significance between curves $(P=.050)$. By using a cutoff of 47 or greater for Fitzpatrick and colleagues' score, the sensitivity and specificity for predicting long-term RVAD treatment in our population were $78 \%$ (95\% CI, 53-94) and 100\% (95\% CI, 79-100), respectively.

\section{DISCUSSION}

The present study supports the safety and efficacy of BiVAD as a bridge to HTx in selected patients with a high risk for postimplant RV failure. Survival among patients treated with BiVAD was higher than previously reported and similar to that observed for contemporary LVAD recipients, despite those receiving BiVAD being more severely ill. The frequency of adverse events was 


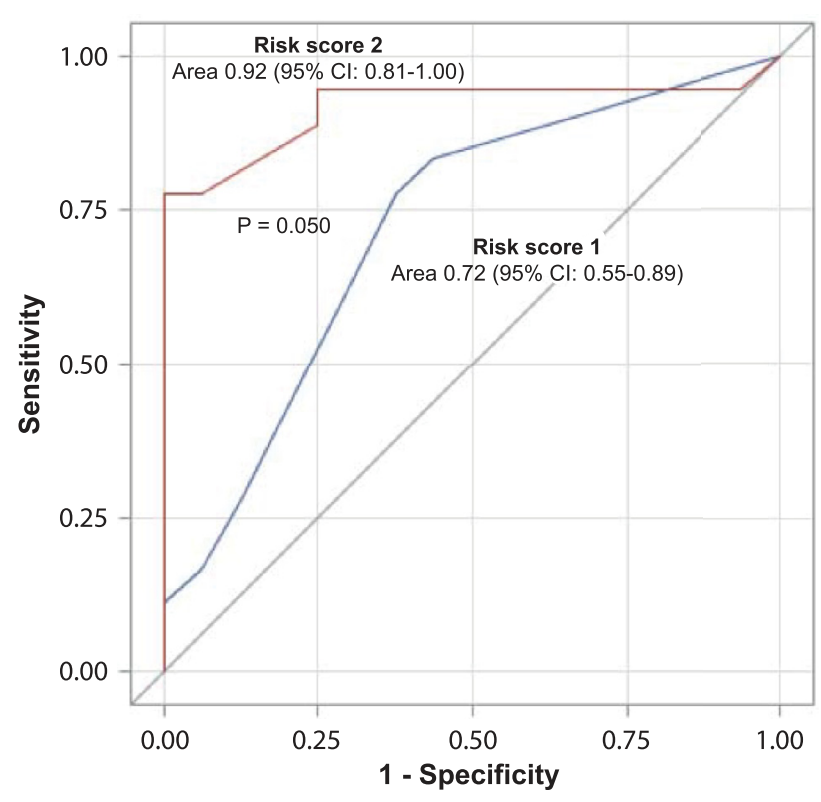

FIGURE 3. ROC curves for RV failure risk score 1 (Matthews and colleagues $^{6}$ ) and risk score 2 (Fitzpatrick and colleagues ${ }^{7}$ ).

comparable between the 2 groups, and the majority of patients in both treatment arms could be discharged to home during the waiting time to HTx.

$\mathrm{RV}$ failure, which is one of the most important risk factors for mortality and morbidity after LVAD therapy, ${ }^{10-12}$ may occur in up to $50 \%$ of patients. ${ }^{1}$ Still, less than $5 \%$ of primary MCS implants in the INTERMACS registry are reported as a BiVAD. ${ }^{13}$ Therefore, we speculate that many centers may not evaluate patients for a BiVAD as a bridge to transplantation despite a high risk for postimplant RV failure. Strategies used to aid RV recovery after LVAD implantation include inotropic support, unloading with pulmonary vasodilatative therapy, ${ }^{14,15}$ and temporary RV assists. ${ }^{16-18}$ However, patients in need of such therapy show impaired survival ${ }^{3,10,12,19}$ and have longer stays in intensive care units (ICUs). ${ }^{10}$ In a study by Takeda and colleagues,${ }^{17}$ more than half of the patients who required an unplanned RVAD after LVAD insertion could not be weaned form biventricular support. These patients displayed ongoing end-organ dysfunction after RVAD implantation and had a dismal prognosis with a 6-month survival of only $16 \%$. An additional negative factor is that RV failure after LVAD implantation may contribute to deterioration of end-organ function to the degree that eligibility for and outcomes after HTx are affected. ${ }^{12,17}$

At our center, average wait times for HTx are short. We have chosen to implant a BiVAD directly in patients considered at a high risk for postimplant RV failure. Our main selection criteria for preplanned BiVAD are clinical, echocardiographic, and hemodynamic signs of poor RV function, as well as INTERMACS profile 1, ongoing short-term assist, and signs of multiple organ failure. After MCS implantation, patients normally undergo 3 months of rehabilitation for general optimization and end-organ recovery before they are actively listed for a heart transplant.

Sahlgrenska University Hospital is a heart transplant referral center serving western and northern Sweden with a population of approximately 3.5 million, and frequently receives patients in cardiogenic shock for evaluation. Consequently, implantations of short-term MCS, mainly ECMO, have increased. We avoid performing HTx directly from short-term support, because such patients are exposed to an increased risk of postoperative complications and mortality. ${ }^{20,21}$ Instead, we have adopted the policy to convert these patients to long-term devices and list them first after end-organ recovery, rehabilitation, and home discharge. A high proportion of our patients receiving durable MCS receive implants from INTERMACS levels 1 or are converted from a short-term assist. The poor outcomes after LVAD implantations in such patients ${ }^{13}$ have driven us toward a higher use of BiVADs, which constituted approximately half of the durable MCS implanted in this study. We postulated that this strategy would reduce perioperative risks, minimize organ waste, and result in better post-transplant outcomes.

In the present study, $90 \%$ of BiVAD recipients survived to transplantation/weaning and $85 \%$ were alive after 1 year. This was comparable to that observed among LVAD recipients. Our results are particularly noteworthy considering that the BiVAD recipients were hemodynamically more compromised and more often had multiple organ failure. Earlier studies have reported a survival to transplantation of approximately $50 \%$ among patients receiving BiVAD, ${ }^{17,22}$ which may explain why many centers hesitate to use biventricular support. A recent retrospective study based on data from the United Network Organ Sharing registry ${ }^{23}$ reported a 6-month survival for BiVAD recipients of only $68 \%$. Significant regional heterogeneity in the use of different BiVAD configurations was observed, suggesting a large variation in center preference with respect to device choice. The reasons for the favorable outcomes among our BiVAD recipients are probably multifactorial. We conclude that our well-defined strategy of "preplanned" rather than "delayed" biventricular support, the use of only 1 device type, active rehabilitation with home discharge, meticulous care of cannula exit sites, and short waiting times for transplantation are likely to have contributed.

For both study groups, the median time in the ICU was approximately 1 week. Our first BiVAD recipients were treated in hospital before transplantation. This policy was modified when it became apparent that BiVAD recipients could be managed on an outpatient basis similarly to LVAD recipients. Thus, before being placed on the HTx waiting list, the majority of patients in both groups could 
be discharged to home. BiVAD recipients were prioritized on the waiting list, and for these patients, the median time from device implant to transplantation was approximately 5 months. The median time from implantation to transplant for LVAD recipients was approximately 10 months.

A study based on data from the INTERMACS registry ${ }^{24}$ reported a significantly higher rate of serious adverse events among BiVAD recipients compared with those treated with LVAD. However, the investigators were not able to separate preplanned versus unplanned BiVAD support. In the present study, the absolute frequency of complications including thromboembolism, neurologic events, and infections was fairly low and similar in both groups. Still, the rate of adverse events tended to be somewhat higher in the BiVAD group when adjusted for time on device. There was 1 case of BiVAD system membrane rupture occurring after home discharge, which was resolved with acute ECMO support followed by pump exchange. ${ }^{9}$ Significant RV failure after implantation developed in 5 LVAD recipients, of whom 2 died early (day 30 and day 49) and 3 were converted to long-term biventricular support. These patients required a prolonged ICU stay and total hospitalization, exemplifying the deleterious consequences of postimplant RV failure.

Patient selection for BiVAD support as a bridge to transplantation is important but highly complex because several different factors may predict RV failure in LVAD recipients. In our study, BiVAD recipients, compared with LVAD recipients, were younger, more often female, and more frequently had nonischemic heart disease. BiVAD recipients had a higher central venous pressure/PCW ratio, lower RVSWI, and more frequently displayed INTERMACS profiles 1 to 2. All of these characteristics have been identified as RV failure risk factors after LVAD implantation. ${ }^{5,7,18,25}$

The present study population also was used to evaluate 2 different RV failure risk scores. These scores were not used at the time the decision to use MCS was made, instead they were calculated retrospectively. The risk score described by Matthews and colleagues ${ }^{6}$ showed suboptimal discrimination power with respect to our 2 device populations with an ROC AUC of $72 \%$. The risk score suggested by Fitzpatrick and colleagues ${ }^{7}$ differentiated well between patients receiving BiVAD support, either preplanned or converted, and those managed with LVAD alone. The ROC AUC was $92 \%$. This would support the usefulness of this risk model as an aid when determining treatment strategy in our population. In other settings, however, this risk score has been found to perform poorly with respect to prediction of postimplant RV failure. ${ }^{26}$

Implantation of an LVAD, compared with a BiVAD, is associated with less-demanding implantation techniques, lower device costs, and less patient discomfort during long-term support. This, along with previous reports on unfavorable outcome after BiVAD insertion, ${ }^{19}$ may explain why most centers prefer to insert only an LVAD despite a high risk for RV failure or reject such patients for ventricular assist device treatment altogether. On the basis of the findings of the present study, we believe that BiVAD is underused as a bridge to transplantation. In patients with a high risk of postimplant RV failure, a strategy with preplanned BiVAD is likely to improve survival to transplantation, decrease time in intensive care, reduce total hospital stay, and thereby reduce overall costs. Because patient discomfort while on pulsatile BiVAD support is significant, heart transplant list waiting times preferably should not exceed 1 year. There have been a few reports about the use of implantable continuous flow pumps as biventricular support. ${ }^{27,28}$ This strategy may offer greater patient comfort compared with extracorporeal pulsatile pumps, and thereby allow for longer HTx waiting times. However, further studies are necessary to define the role of this approach, as well as the use of a total artificial heart in the context of bridge to transplantation.

\section{Study Limitations}

The observational, retrospective nature of the present study is an important limitation with respect to the degree of evidence we can provide. Also, small sample sizes and the differences in age, gender, body size, and heart failure cause between the 2 study groups constrain our conclusions. Time on device was shorter for BiVAD recipients than for LVAD recipients, which affects the comparison of adverse events between groups. Still, time on device is not entirely conclusive when comparing complications, because most of pump-related morbidity and mortality occurs early after implantation. We did not use uniform criteria to select the treatment strategy of BiVAD or LVAD. Instead, the decision was based on the estimated risk for postimplant RV failure after a multidisciplinary evaluation of clinical, echocardiographic, and hemodynamic data.

\section{CONCLUSIONS}

Planned in advance, BiVAD appears to be a feasible strategy for a bridge to HTx for selected patients with a high risk for RV failure. Under these circumstances, this approach is likely to reduce hospital stay and improve survival to HTx with a complication rate similar to that observed in patients with adequate RV function who are managed with an LVAD alone. To avoid the deleterious consequences of postimplant RV failure, we believe that preplanned BiVAD should be used with greater frequency.

\section{Conflict of Interest Statement}

K.K. has received lecture fees from AstraZeneca and Orion Pharma. All other authors have nothing to disclose with regard to commercial support.

Jonathan D. Stubbs, MSc, CRC, reviewed the English used in this article. 


\section{References}

1. Drakos SG, Janicki L, Horne BD, Kfoury AG, Reid BB, Clayson S, et al. Risk factors predictive of right ventricular failure after left ventricular assist device implantation. Am J Cardiol. 2010;105:1030-5.

2. Aissaoui N, Morshuis M, Paluszkiewicz L, Lauenroth V, Borgermann J, Gummert J. Comparison of biventricular and left ventricular assist devices for the management of severe right ventricular dysfunction in patients with end-stage heart failure. ASAIO J. 2014;60:400-6.

3. Kormos RL, Teuteberg JJ, Pagani FD, Russell SD, John R, Miller LW, et al. Right ventricular failure in patients with the HeartMate II continuous-flow left ventricular assist device: incidence, risk factors, and effect on outcomes. J Thorac Cardiovasc Surg. 2010;139:1316-24.

4. Fitzpatrick JR 3rd, Frederick JR, Hiesinger W, Hsu VM, McCormick RC, Kozin ED, et al. Early planned institution of biventricular mechanical circulatory support results in improved outcomes compared with delayed conversion of a left ventricular assist device to a biventricular assist device. J Thorac Cardiovasc Surg. 2009; 137:971-7.

5. Ochiai Y, McCarthy PM, Smedira NG, Banbury MK, Navia JL, Feng J, et al. Predictors of severe right ventricular failure after implantable left ventricular assist device insertion: analysis of 245 patients. Circulation. 2002;106:I198-202.

6. Matthews JC, Koelling TM, Pagani FD, Aaronson KD. The right ventricular failure risk score a pre-operative tool for assessing the risk of right ventricular failure in left ventricular assist device candidates. J Am Coll Cardiol. 2008;51: 2163-72.

7. Fitzpatrick JR 3rd, Frederick JR, Hsu VM, Kozin ED, O'Hara ML, Howell E, et al. Risk score derived from pre-operative data analysis predicts the need for biventricular mechanical circulatory support. J Heart Lung Transplant. 2008; 27:1286-92.

8. Stevenson LW, Pagani FD, Young JB, Jessup M, Miller L, Kormos RL, et al. INTERMACS profiles of advanced heart failure: the current picture. J Heart Lung Transplant. 2009:28:535-41.

9. Volz S, Holmberg M, Redfors B, Dellgren G. Acute tamponade of the left paracorporeal pump house due to membrane defect in a patient with a Berlin Heart EXCOR biventricular assist device. Eur J Cardiothorac Surg. 2014;46: 743-4.

10. Dang NC, Topkara VK, Mercando M, Kay J, Kruger KH, Aboodi MS, et al. Right heart failure after left ventricular assist device implantation in patients with chronic congestive heart failure. J Heart Lung Transplant. 2006;25:1-6.

11. Kormos RL, Gasior TA, Kawai A, Pham SM, Murali S, Hattler BG, et al. Transplant candidate's clinical status rather than right ventricular function defines need for univentricular versus biventricular support. J Thorac Cardiovasc Surg. 1996; 111:773-83.

12. Morgan JA, John R, Lee BJ, Oz MC, Naka Y. Is severe right ventricular failure in left ventricular assist device recipients a risk factor for unsuccessful bridging to transplant and post-transplant mortality. Ann Thorac Surg. 2004;77:859-63.

13. Kirklin JK, Naftel DC, Pagani FD, Kormos RL, Stevenson LW, Blume ED, et al. Seventh INTERMACS annual report: 15,000 patients and counting. J Heart Lung Transplant. 2015;34:1495-504.

14. Tedford RJ, Hemnes AR, Russell SD, Wittstein IS, Mahmud M, Zaiman AL, et al. PDE5A inhibitor treatment of persistent pulmonary hypertension after mechanical circulatory support. Circ Heart Fail. 2008;1:213-9.

15. Wagner F, Dandel M, Gunther G, Loebe M, Schulze-Neick I, Laucke U, et al. Nitric oxide inhalation in the treatment of right ventricular dysfunction following left ventricular assist device implantation. Circulation. 1997;96: II-291-296.

16. Bhama JK, Kormos RL, Toyoda Y, Teuteberg JJ, McCurry KR, Siegenthaler MP Clinical experience using the Levitronix CentriMag system for temporary righ ventricular mechanical circulatory support. J Heart Lung Transplant. 2009;28: 971-6.

17. Takeda K, Naka Y, Yang JA, Uriel N, Colombo PC, Jorde UP, et al. Outcome of unplanned right ventricular assist device support for severe right heart failure after implantable left ventricular assist device insertion. J Heart Lung Transplant. 2014:33:141-8.

18. Kavarana MN, Pessin-Minsley MS, Urtecho J, Catanese KA, Flannery M, $\mathrm{Oz} \mathrm{MC}$, et al. Right ventricular dysfunction and organ failure in left ventricular assist device recipients: a continuing problem. Ann Thorac Surg. 2002;73: 745-50.

19. Kirklin JK, Naftel DC, Pagani FD, Kormos RL, Stevenson LW, Blume ED, et al Sixth INTERMACS annual report: a 10,000-patient database. J Heart Lung Transplant. 2014:33:555-64.

20. Barge-Caballero E, Almenar-Bonet L, Villa-Arranz A, et al. Impact of short-term mechanical circulatory support with extracorporeal devices on postoperative outcomes after emergency heart transplantation: data from a multi-institutional Spanish cohort. Int J Cardiol. 2014;176:86-93.

21. Mohite PN, Zych B, Banner NR, Simon AR. Refractory heart failure dependent on short-term mechanical circulatory support: what next? Heart transplant or long-term ventricular assist device. Artif Organs. 2014;38:276-81.

22. Farrar DJ, Hill JD, Pennington DG, Perez-Villa F, Segovia-Cubero J, DelgadoJimenez J, et al. Preoperative and postoperative comparison of patients with univentricular and biventricular support with the Thoratec ventricular assist device as a bridge to cardiac transplantation. J Thorac Cardiovasc Surg. 1997;113: 202-9.

23. Levin AP, Jaramillo N, Garan AR, Takeda K, Takayama H, Yuzefpolskaya M et al. Outcomes of contemporary mechanical circulatory support device configurations in patients with severe biventricular failure. J Thorac Cardiovasc Surg. 2016;151:530-5.e532.

24. Cleveland JC Jr, Naftel DC, Reece TB, Murray M, Antaki J, Pagani FD, et al. Survival after biventricular assist device implantation: an analysis of the Interagency Registry for Mechanically Assisted Circulatory Support database. J Heart Lung Transplant. 2011;30:862-9.

25. Patil NP, Mohite PN, Sabashnikov A, Dhar D, Weymann A, Zeriouh M, et al. Preoperative predictors and outcomes of right ventricular assist device implantation after continuous-flow left ventricular assist device implantation. J Thorac Cardiovasc Surg. 2015;150:1651-8.

26. Pettinari M, Jacobs S, Rega F, Verbelen T, Droogne W, Meyns B. Are right ventricular risk scores useful? Eur J Cardiothorac Surg. 2012;42:621-6.

27. Strueber M, Meyer AL, Malehsa D, Haverich A. Successful use of the HeartWare HVAD rotary blood pump for biventricular support. J Thorac Cardiovasc Surg. 2010;140:936-7.

28. Krabatsch T, Potapov E, Stepanenko A, Schweiger M, Kukucka M, Huebler M et al. Biventricular circulatory support with two miniaturized implantable assist devices. Circulation. 2011;124:S179-86.

Key Words: complications, heart failure, survival, transplantation, ventricular assist device 

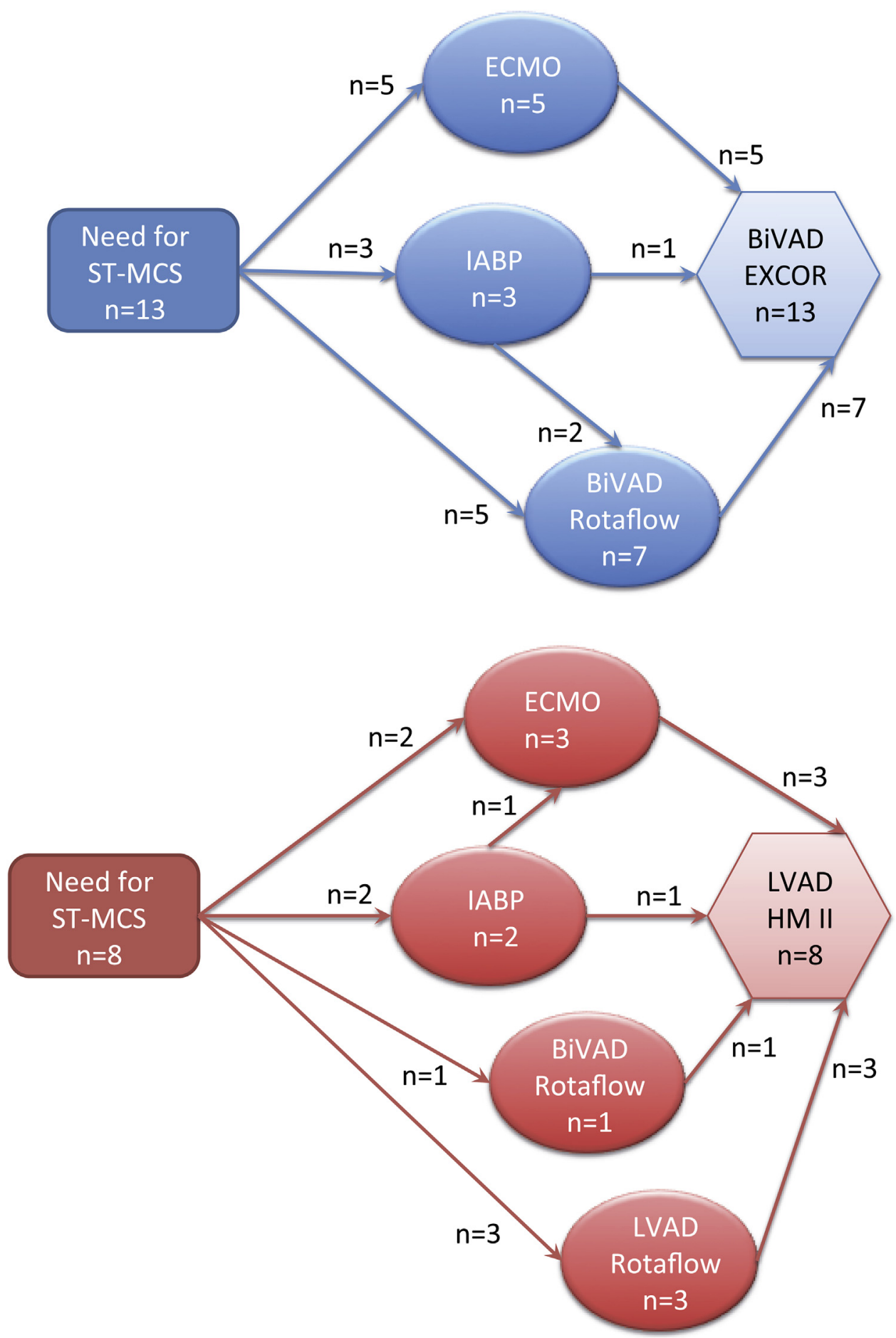

FIGURE E1. Different types of short-term MCS devices used in the BiVAD and LVAD recipients before conversion to durable mechanical support. $E C M O$, Extracorporeal membrane oxygenation; ST-MCS, short-term mechanical circulatory support; IABP, intra-aortic balloon pump; BiVAD, biventricular assist device; $L V A D$, left ventricular assist device. Rotaflow is the Rotaflow PLS system (Maquet, Germany). 